\title{
Can mitral regurgitation after balloon dilatation of the mitral valve be predicted?
}

\author{
Mohan Nair, Rajeev Agarwala, G S Kalra, R Arora, M Khalilullah
}

\begin{abstract}
Objective-To determine which factors predict the occurrence of mitral regurgitation after balloon dilatation of the mitral valve for rheumatic stenosis.

Design-Analysis of a case series of patients with rheumatic mitral valve stenosis who had had successful balloon dilatation of the mitral valve.
\end{abstract}

Setting-A tertiary care centre with an experience of over 150 balloon dilatations of the mitral valve.

Patients-70 young patients with noncalcified rheumatic mitral stenosis, who had undergone successful balloon dilatation of the mitral valve. No patient had mitral regurgitation or atrial fibrillation before dilatation.

Intervention-Dilatation of the mitral valve by the transvenous, transatrial double balloon technique.

Main outcome measure-Development of mitral regurgitation after balloon dilatation of the mitral valve and its relation to age, mitral valve area before dilatation and after dilatation, the degree of mitral subvalvar pathology, and the size of balloon used for dilatation.

Results In 10 patients (14\%) mitral regurgitation developed after balloon dilatation of the mitral valve. No statistically significant differences were found between patients who did not develop regurgitation and those who did in terms of age (mean (SD)) (19.9 (6.46) $v \quad 19.4$ (5.5)), mitral valve area before dilatation $\left(1.05(0.33) v 0.94(0.4) \mathrm{cm}^{2}\right)$ and after dilatation $\left(2.52(1.06)\right.$ v $\left.2.45(1.1) \mathrm{cm}^{2}\right)$, mitral subvalvar pathology assessed by the mitral subvalvar distance ratio $(0 \cdot 116$ $(0.03) v 0.118(2.32)$, or balloon diameter corrected for body surface area (21.37 (3.5) $v 20.57(2.32) \mathrm{mm} / \mathrm{m}^{2}$.

Conclusions-In this subset of children and young adults with non-calcified mitral stenosis, none of the morphological, technical, or patient characteristics studied predicted the development of mitral regurgitation after balloon dilatation. The low incidence of mitral regurgitation may have reduced the discriminatory power of this study. None the less, the means and standard deviation for each factor in each group suggest that even in a larger sample size the variables would have little predictive capacity.
Balloon dilatation of the mitral valve has emerged as an effective non-surgical technique for the treatment of rheumatic mitral stenosis. ${ }^{1-3}$ Mitral regurgitation after balloon dilatation is reported to occur in about $20-53 \%$ of patients. ${ }^{4-6}$ Though it is mild in most, this procedure-induced regurgitation has led to concern about the safety of dilatation. We reviewed a series of 70 patients who had balloon dilatation of the mitral valve at our hospital to determine whether certain important technical factors or features of valve morphology predicted the development of mitral regurgitation after balloon dilatation.

Patients and methods

We reviewed data on 70 patients with pure rheumatic mitral stenosis (25 male and 45 female, aged 10-30 (mean (SD) 19.2 (6.4) years) who had balloon dilatation of the mitral valve. All patients underwent percutaneous balloon dilatation of the mitral valve by the anterograde, trans-septal route by the double balloon technique described earlier. ${ }^{4}$ Mitral regurgitation was assessed before and after the procedure by left ventricular cineangiogram in $30^{\circ}$ right anterior oblique view. The degree of mitral regurgitation was graded as $1+$ to $4+$ by the method described by Grossman. ${ }^{7}$ The following factors were analysed retrospectively to examine their relation to mitral regurgitation induced by the procedure: $(a)$ age, $(b)$ severity of mitral stenosis before balloon dilatation, (c) mitral valve area achieved after dilatation, (d) effective balloon diameter $/ \mathrm{m}^{2}$ of body surface area, and (e) degree of mitral subvalvar pathology. Mitral subvalvar pathology was assessed on the left ventricular cineangiogram and expressed as the mitral subvalvar distance ratio (the ratio of the distance from the mitral valve to the tip of the papillary muscle in end diastole to the distance from the aortic valve to the left ventricular apex in end diastole ${ }^{8}$ (figure).

\section{STATISTICAL ANALYSIS}

The distribution of the various factors studied in patients in whom mitral regurgitation developed after balloon dilatation of the mitral valve and in patients in whom it did not were compared by Students $\chi^{2}$ test. A $p$ value of $<0.05$ was regarded as statistically significant.

\section{Results}

All patients were in sinus rhythm and had moderate to severe mitral stenosis (valve area $0.5-1.5 \mathrm{~cm}^{2}$, mean (SD) $\left.0.96(0.35) \mathrm{cm}^{2}\right)$ before

Department of
Cardiology,
G B Pant Hospital,
New Delhi, India
M Nair
R Agarwala
G S Kalra
R Arora
M Khalilullah
Correspondence to:
Professor R Arora,
Department of Cardiology
G B Pant Hospital, New
Delhi - 110 002, India.
Accepted for publication
5 September 1991




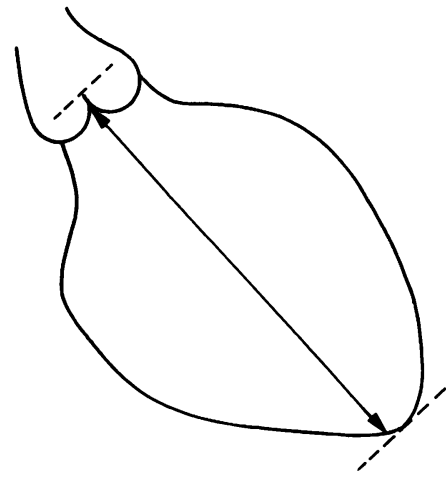

Aortic valve to

left ventricular apex in diastole (AV-LVA)

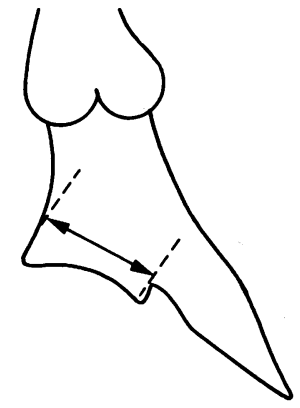
papillary muscle tip in systole (MV-PM)
Mitral valve to

Mitral subvalvar distance ratio
$(\mathrm{MSDR})$

Method for determining the mitral subvalvar distance ratio.

Characteristics (mean (SD)) of patients with and without mitral regurgitation (MR) after balloon dilatation

\begin{tabular}{lcc}
\hline Variable & $\begin{array}{l}\text { No } M R \\
(n=60)\end{array}$ & $\begin{array}{l}M R \\
(n=10)\end{array}$ \\
\hline Age & $19.9(6.46)$ & $19.4(5.5)$ \\
MVA before $\left(\mathrm{cm}^{2}\right)$ & $1.05(0.33)$ & $0.94(0.4)$ \\
MVA after $\left(\mathrm{cm}^{2}\right)$ & $2.52(1.06)$ & $2.45(1.1)$ \\
Distance ratio & $0.116(0.03)$ & $0.118(0.02)$ \\
EDB/BSA $\left(\mathrm{mm} / \mathrm{m}^{2}\right)$ & $21.37(3.5)$ & $20.75(2 \cdot 32)$ \\
\hline
\end{tabular}

MVA, mitral valve area; EBD, effective balloon diameter; $B S A$, body surface area.

dilatation. After dilatation the mitral valve area increased significantly $(\mathrm{p}<0.001)$ to $1.4-4.08$ $\mathrm{cm}^{2}$ (mean (SD) $\left.2 \cdot 3(0 \cdot 83) \mathrm{cm}^{2}\right)$.

\section{MITRAL REGURGITATION}

No patient had mitral regurgitation before balloon dilatation. After dilatation mitral regurgitation was seen in $10(14 \%)$ patients. Mitral regurgitation was $1+$ in eight patients and $2+$ in two patients. Mitral regurgitation was well tolerated haemodynamically in all 10 patients and no patient required mitral valve replacement for this complication.

\section{RELATION OF MITRAL REGURGITATION TO VARIOUS FACTORS}

A comparison of patients with procedureinduced mitral regurgitation $(n=10)$ and those without $(n=60)$ showed no statistically significant difference for any of the variables assessed (table).

\section{Discussion}

Mitral regurgitation caused by balloon dilatation is seen in about $20 \%$ of patients ${ }^{9}$ and is an important potential complication of the procedure. The patients in our study were much younger than those in other large series, and new mitral regurgitation in younger patients may be expected to be more harmful in the long term. This is why we thought it important to determine the frequency of mitral regurgitation after balloon dilatation, so that we could change patient selection and/or the technique if necessary.

We found new regurgitation in $14 \%$ of our patients. This incidence is slightly lower than that reported by Abascal $e t a P$ and Nobuyoshi et $a l^{t}$; the difference may be explained by the different age group studied and the absence of calcified mitral stenosis in our study. As in the other studies, most instances of mitral regurgitation after balloon dilatation were mild. Not one had $3+$ or $4+$ mitral regurgitation. We did not find any significant difference in the age, severity of mitral stenosis before dilatation, mitral valve area achieved, balloon size used, or the extent of mitral subvalvar pathology between patients in whom mitral regurgitation developed and those in whom it did not. Abascal et al also found no association between the production or worsening of regurgitation and valve and subvalvar morphology, balloon size, age, sex, initial mitral valve area or increase in mitral valve area or both. ${ }^{5}$ Nobuyoshi et al, however, reported that mitral regurgitation was less frequent and less severe in patients with a pliable valve, while in patients with semipliable or rigid valves the incidence and severity of clinically important mitral regurgitation increased. ${ }^{6}$ Most of our patients had moderate degree of subvalvar pathology - and, therefore, the mitral valve morphology may have been significantly different from that in the study by Nobuyoshi $e t$ al. Vahanian et al also reported that severe (but not mild or moderate) mitral regurgitation after balloon dilatation correlated with anatomical features such as calcified valves and extensive subvalvar disease. ${ }^{10}$ None of our patients had calcified mitral stenosis nor did balloon dilatation cause any cases of severe mitral regurgitation.

We did not identify any statistically significant differences between the means of the measured technical or morphological variables in patients with mitral regurgitation after balloon dilatation and those without. Because only 10 patients developed mitral regurgitation the power of these tests was low. However, the means (SD) in the table suggest that even if a significant difference was found for any of the variables in a larger sample there would still be substantial overlap between the two distributions and hence the variable would have little predictive capacity.

1 Roy SB, Bhatia ML, Lorazo EJ, Ramalingaswami V. Juvenile mitral stenosis in India. Lancet 1963;ii:1193-5. Kraus F, Dacihn S, Friedricks W, Ruolf C, Halld RW. Haemodynamic results of mitral valvuloplasty compared with commissurotomy and valve replacement. Circulation 1987;76 (suppl IV):IV-89.

3 Lock JE, Khalilllah M, Srivastava S, Bahl V, Keane JF. Percutaneous catheter commissurotomy in rheumatic mitral stenosis. N Engl J Med 1985;313:1515-8

4 Arora R, Nair M, Rajagopal S, Sethi KK, Mohan JC, Nigam $M$,et al. Percutaneous mitral valvuloplasty in children and ,et al. Percutaneous mitral valvuloplasty in children and young adults with

5 Abascal VM, Wilkins GT, Choong CY, Bloc PC, Palacios IF, Weyman AE. Mitral regurgitation after percutaneous balloon mitral valvuloplasty in adults; evaluation by pulsed Doppler ech 
6 Nobuyoshi M,Hamasaki N, Kimiura T, Nosaka H, Yokoi H, Yasumoto $\mathrm{H}$, et al. Indications, complications and shor term clinical outcome of percutaneous transvenous mitra commissurotomy. Circulation 1989;80:4:782-92.

7 Grossman W. Profiles in valvular heart disease. In: Grossman W, ed. Cardiac catheterization and angiography. 3rd ed. Philadelphia: Lea \& Fabiger, 1986:365-6.

8 Akins CW, Kirklin JK, Block PC, Buckley MJ, Austen WG

Preoperative evaluation of subvalvular fibrosis in mitral
stenosis. A predictive factor in conservative $3 \mathrm{Vs}$ re- placement surgical therapy. Circulation 1979 (suppl I): $71-6$

9 Abascal VM, Wilkins G, Choong CY, Thomas JD, Palacios IF, Block PC, et al. Echocardiographic evaluation of mitral valve structure and function of patients followed for at least 6 months after percutaneous balloon mitral valvuloplasty. J Am Coll Cardiol 1988;12:606-15.

10 Vahanian A, Michel PL, Cormier B, Viloux B, Michel X, Slama M, et al. Results of percutaneous mitral commissurotomy in 200 patients. Am J Cardiol 1989;63:847-52. 